High cyclin A expression, but not Ki67, is associated with early recurrence in desmoid tumors

\title{
Santti, Kirsi
}

2018-07-01

Santti , K, Ihalainen , H , Ronty , M , Boehling , T, Karlsson , C , Haglund, C , Tarkkanen , M \& Blomqvist , C 2018 , ' High cyclin A expression, but not Ki67, is associated with early recurrence in desmoid tumors ' , Journal of Surgical Oncology , vol. 118 , no. 1 , pp. 192-198 . https://doi.org/10.1002/jso.25121

http://hdl.handle.net/10138/305620

https://doi.org/10.1002/jso.25121

unspecified

publishedVersion

Downloaded from Helda, University of Helsinki institutional repository.

This is an electronic reprint of the original article.

This reprint may differ from the original in pagination and typographic detail.

Please cite the original version. 


\title{
High cyclin A expression, but not Ki67, is associated with early recurrence in desmoid tumors
}

\author{
Kirsi Santti MD ${ }^{1}$ (1) $\mid$ Hanna Ihalainen $\mathrm{MD}^{1,2} \mid$ Mikko Rönty MD, $\mathrm{PhD}^{3}$ | \\ Tom Böhling MD, PhD ${ }^{3}$ | Christina Karlsson MSc, $\mathrm{PhD}^{4}$ | Caj Haglund MD, PhD ${ }^{5,6}$ | \\ Maija Tarkkanen MD, PhD $^{1}$ | Carl Blomqvist MD, PhD ${ }^{1,7}$
}

\author{
${ }^{1}$ Comprehensive Cancer Center, Helsinki \\ University Hospital and University of Helsinki, \\ Helsinki, Finland \\ ${ }^{2}$ Department of Plastic Surgery, Helsinki \\ University Hospital and University of Helsinki, \\ Helsinki, Finland \\ ${ }^{3}$ Department of Pathology, HUSLAB and \\ University of Helsinki, Helsinki, Finland \\ ${ }^{4}$ Department of Medical Diagnostics, \\ School of Health Sciences, Örebro University, \\ Örebro, Sweden \\ ${ }^{5}$ Department of Surgery, Helsinki University \\ Hospital and University of Helsinki, Helsinki, \\ Finland \\ ${ }^{6}$ Reseach Program Unit, Translational Cancer \\ Biology, University of Helsinki, Helsinki, \\ Finland \\ ${ }^{7}$ Department of Oncology, Örebro University \\ Hospital, Örebro, Sweden

\section{Correspondence} \\ Kirsi Santti, Comprehensive Cancer Center, \\ Helsinki University Hospital, PO Box 180, \\ 00029 HUS, Helsinki, Finland. \\ Email: kirsi.santti@hus.fi \\ Funding information \\ Helsinki University Hospital Research funds: \\ Medicinska Understödsföreningen Liv och \\ Hälsa; Finnish Society for Oncology; Finska \\ Läkaresällskapet; Sigrid Juséliuksen Säätiö
}

Background and Objectives: Desmoid tumors are soft-tissue tumors originating from myofibroblasts with a tendency to recur after surgery. High expression of proliferation markers is associated with shortened progression-free and/or overall survival in many neoplasms, including soft-tissue sarcomas. We investigated the prognostic role of cyclin A and Ki67 in desmoid tumors by immunohistochemistry. Methods: The study included 76 patients with desmoid tumor operated at Helsinki University Hospital between 1987 and 2011. A tissue micro array (TMA) was constructed and the TMA sections were immunostained with cyclin $A$ and Ki67 antibodies. A computer-assisted image analysis was performed.

Results: Cyclin A expression was evaluable in 74 and Ki67 in 70 patients. Cyclin A immunopositivity varied from $0 \%$ to $9.9 \%$, with a mean of $1.9 \%$. Cyclin A expression correlated significantly with Ki67. Cyclin A expression was associated with recurrencefree survival ( $\mathrm{HR} 1.9,95 \% \mathrm{Cl}=1.1-3.2, P=.02)$, as were positive margin $(\mathrm{HR} 6.0,95 \% \mathrm{Cl}$ $=1.6-22.5, P=.008$ ) and extremity location ( $\mathrm{HR} 5.3,95 \% \mathrm{Cl}=1.7-16.8, \mathrm{P}=0.005)$. Ki67 immunopositivity varied from $0.33 \%$ to $13.8 \%$, with a mean of $4.6 \%$, but had no significant prognostic impact (HR 1.1, $P=.2$ ).

Conclusions: Our study indicates that cyclin A may be a new prognostic biomarker in surgically treated desmoid tumors.

KEYWORDS

aggressive fibromatosis, biomarkers, cyclins, immunohistochemistry, prognostic factors

\section{1 | INTRODUCTION}

Neoplastic growth depends on the proliferation rate, the number of quiescent cells, and apoptosis. The cellular proliferation marker cyclin A2 activates the cyclin-dependent kinases 1 or 2, which, as a complex, regulates the cell cycle. The complex phosphorylates serine or threonine in the $S$ phase during DNA replication as well as in the transition from the $\mathrm{G} 2$ phase to mitosis. Cyclin-dependent kinases inhibitors have been investigated for anticancer therapy. The first approved cyclin-dependent kinases4/6 inhibitor was palbociclib in metastatic breast cancer. ${ }^{1,2}$
Ki67, the clinically most commonly used proliferation marker, is a cell cycle regulator present throughout all the active phases of division, indicating the proportion of proliferative cells.

Desmoid tumors are infiltrative mesenchymal tumors with an unpredictable clinical behavior. Active surveillance is the strategy for patients with nonprogressive and symptomless tumors. Other management options include surgery, radiotherapy, and/or medical therapy. ${ }^{3}$ Approximately $95 \%$ of sporadic desmoids carry a mutation in the $\beta$-catenin CTNNB1 or the APC gene. ${ }^{4}$ Patients with familial adenomatous polyposis (FAP) harbor a germline APC mutation that 
predisposes to the development of desmoid tumors. ${ }^{5,6}$ Several risk factors for recurrence after surgery have been described. A recent literature survey indicated that young age and positive surgical margins are prognostic for recurrence in multivariate analysis. Tumor size was prognostic in 2 of the 4 studies testing size in multivariate analysis. ${ }^{7}$ In a meta-analysis of 1295 patients with surgically treated extra-abdominal desmoid tumors, a positive resection margin was associated with a higher recurrence rate. Adjuvant radiotherapy after surgery with positive margins decreased the recurrence rate. ${ }^{8}$ Another multivariate analysis of 495 patients also identified extremity location but not surgical margin as a prognostic factor for recurrence. ${ }^{9}$

High Ki67 and cyclin A are associated with a poor prognosis in breast cancer, prostate carcinomas, and soft-tissue sarcomas. ${ }^{10-12}$ However, the role of proliferation in desmoid tumors has not been clearly defined. Ki67 expression in desmoid tumors has been assessed using various techniques and cut-off points, with inconsistent results. To our knowledge, cyclin A expression has not been evaluated in desmoid tumors. This work aims to assess the prognostic value and association of $\mathrm{Ki} 67$ and cyclin A by immunohistochemistry with clinicopathological parameters in desmoid tumors.

\section{MATERIAL AND METHODS}

\section{1 | Patients}

The study included 90 patients with desmoid tumors referred to Helsinki University Hospital between 1987 and 2011. Clinical data were retrieved from patient charts and databases. An experienced sarcoma pathologist (MR) re-evaluated the diagnostic specimens. Patients lacking clinical data or follow-up were excluded, as was one patient with an incorrect diagnosis on review. The study was approved by the Ethics Committee of Helsinki University Hospital (270/13/03/00/2011) and the National Supervisory Authority for Welfare and Health. The study was conducted in accordance with the Helsinki Declaration.

\section{2 | Tissue arrays and immunohistochemistry}

The tissue micro array (TMA) was generated from formalin-fixed paraffin-embedded surgical specimens. The pathologist (MR) selected the representative tumor areas for punching, and 3 or more $1 \mathrm{~mm}$ punches were obtained from each tumor. Punching was carried out using a manual microarrayer (BeecherInstruments Inc, Silver Spring, MD). Three parallel tissue array blocks were created.

Tissue array blocks were cut into $4 \mu \mathrm{m}$ thick sections and subsequently deparaffinized with xylene and rehydrated with graded concentrations of ethanol. Antigen retrieval was performed in TrisEDTA buffer ( $\mathrm{pH} 9)$ in the pretreatment module by heating sections. Immunostainings were carried out with mouse monoclonal cyclin A antibody (NCL-Cyclin A; Novocastra, Newcastle, UK, dilution 1:50) and anti-Ki67 (anti-human Ki67 Antigen Clone MIB-1; Novocastra, dilution 1:100). Pretreatment and staining were performed with
Autostainer $480 \AA$ (LabVision, Fremont, CA) using the Dako REAL EnVision Detection System ${ }^{\circledR}$, peroxidase/DAB+, Rabbit/Mouse (Glostrup, Denmark). Tissues were incubated for $60 \mathrm{~min}$ with the primary antibodies and for $30 \mathrm{~min}$ with HRP. Counterstaining was performed with hematoxylin and $\mathrm{DAB}+$ and mounted in mounting medium (Pertex ${ }^{\circledR}$, Histolab, Sweden). Tissue specimens from human colon, stomach, and pancreas served as controls.

\section{3 | Immunostainings}

The TMA slides were digitalized using the Pannoramic $250 \AA$ digital scanner (3DHistech, Budapest, Hungary). KS performed the digital image analysis with Pannoramic Viewer ${ }^{\circledR}$ and NuclearQuant ${ }^{\circledR}$ software (3DHistech) for each tumor core blinded from the clinical data. Ki67 and cyclin A expressions were calculated as continuous percentages of immunopositive tumor cell nuclei within the annotated tumor areas. Digitally obtained data were reviewed before inclusion. All specimens with $\geq 300$ neoplastic nuclei were included for analysis. If more than one specimen was acceptable per patient the one with the highest proliferation rate was chosen out of core biopsies with $>500$ tumor cells. In cores with 300-500 tumor cells, the specimen with the highest tumor cell number was selected. Nuclear $\beta$-catenin was immunohistochemically examined and found to be expressed in all tumors.

\section{4 | Statistical analysis}

The SPSS 24® software for Windows (SPSS, Chicago, IL) was used for statistical analysis. The significance of associations between cyclin A, Ki67, and clinicopathological characteristics was determined using Student $t$ test or Pearson's correlation test for dichotomous and continuous variables, respectively. Recurrencefree survival (RFS) was calculated from the first operation with the radical aim of detection of the first recurrence. Two patients with incomplete follow-up data were excluded from the RFS analysis, one of these the only one with $\mathrm{R} 2$ resection. The association of clinical and histological variables with RFS was analyzed in univariate and multivariate Cox regression models. Due to the low number of events, multivariate analyzes with only 1 or 2 factors in addition to cyclin A were performed. The log-rank test was used to compare RFS between high and low cyclin A expression, and the results were visualized as a Kaplan-Meier curve. A 2-tailed $P$-value of .05 was considered significant Determination of optimal cyclin A and Ki67 cut-off values was done by partitioning the patient material at $10 \%$ steps from the 10th to the 90th percentile and calculating the hazard ratio, confidence intervals, and $P$-value at each step.

\section{3 | RESULTS}

Cyclin A and Ki67 were assessable in 74 and 70 of 90 patients, respectively. Fourteen patients were not evaluable for cyclin $A$ or 
Ki67 due to failed staining or low cell number, and were excluded. The median follow-up was 11 years (range from 0.1 to 29 years). Patient and treatment characteristics are shown in Table 1.

\subsection{Expression of cyclin A and Ki67}

Cyclin A immunopositivity varied from $0 \%$ to $9.9 \%$, with a median of $1.5 \%$ and a mean of $1.9 \%$. Ki67 immunopositivity varied from $0.3 \%$ to $13.8 \%$, with a median of $3.9 \%$ and a mean of $4.6 \%$ (Figure 1). Both cyclin A and Ki67 immunostainings were detected only in tumor cell nuclei. Cyclin A significantly correlated with Ki67 $\left(r_{\mathrm{p}}=.79, P<.001\right)$.

\subsection{Associations between clinical characteristics and immunohistochemical expression of cyclin A and $\mathrm{Ki} 67$}

Associations between cyclin A and clinical characteristics are listed in Table 1. High cyclin A expression was associated significantly with tumor size $\left(r_{\mathrm{p}}=.28, P=.03\right)$ and sex $(P=.04)$. There was no correlation between cyclin $A$ expression and patient age, tumor location, resection margin, FAP, pregnancy associated tumor, or postoperative radiotherapy. Ki67 overexpression correlated significantly with age $\left(r_{\mathrm{p}}=-.26, P=.03\right)$, tumor size $\left(r_{\mathrm{p}}=.32, P=.01\right)$, pregnancy-associated tumor $(P=.04)$, and FAP $(P=.001)$. There was

TAB LE 1 Clinical characteristics of 76 patients with surgically treated desmoid tumors and the association of 74 patients' characteristics and cyclin A expression ${ }^{\mathrm{a}}$

\begin{tabular}{|c|c|c|c|c|}
\hline n (\%) & $\begin{array}{l}\text { All } \\
76 \text { (100) }\end{array}$ & $\begin{array}{l}\text { Cyclin A low } \\
60(81)^{\mathrm{a}}\end{array}$ & $\begin{array}{l}\text { Cyclin A high } \\
14 \text { (19) }\end{array}$ & $P$-value \\
\hline Mean age at diagnosis \pm SD & $39 \pm 14$ & $41 \pm 14$ & $33 \pm 13$ & .2 \\
\hline Female & $53(70)$ & $43(72)$ & $8(57)$ & .04 \\
\hline Male & $23(30)$ & $17(28)$ & $6(43)$ & \\
\hline Yes & $11(15)$ & $9(15)$ & $1(7)$ & .1 \\
\hline No & $65(85)$ & $51(85)$ & $13(93)$ & \\
\hline \multicolumn{5}{|l|}{ FAP } \\
\hline Yes & $9(12)$ & $5(8)$ & $4(19)$ & .1 \\
\hline No & $67(88)$ & $55(92)$ & $10(81)$ & \\
\hline Extremities & $15(20)$ & $13(21)$ & $2(15)$ & \\
\hline Head and neck & $4(5)$ & $3(5)$ & $1(7)$ & \\
\hline Trunk & $50(66)$ & $40(67)$ & $8(57)$ & \\
\hline Intra-abdominal & $6(8)$ & $4(7)$ & $2(14)$ & \\
\hline Multifocal & $1(1)$ & $0(10)$ & $1(7)$ & \\
\hline Surgery and margins ${ }^{\mathrm{e}}$ & & & & 1.0 \\
\hline RO & $35(46)$ & $28(47)$ & $5(36)$ & \\
\hline R1 & $23(31)$ & $17(28)$ & $6(43)$ & \\
\hline $\mathrm{R} 2$ & $1(1)$ & $1(2)$ & 0 & \\
\hline
\end{tabular}

${ }^{\mathrm{a} C} \mathrm{Cyclin} \mathrm{A}$ was evaluable in 74 patients.

${ }^{\mathrm{b}}$ The cut-point between low and high cyclin A expression was $2.98 \%$.

${ }^{\mathrm{c}}$ The size of 12 tumors could not be obtained.

${ }^{\mathrm{d}} 0=$ other, 1 = extremities.

${ }^{\mathrm{e}}$ The margins were not recorded in 17 tumors. Statistical testing was performed comparing negative (R0) with positive (R1 and R2) resection margins. The T-test was used for dichotomous variables and Pearson's test was used for continuous variables. FAP, familial adenomatous polyposis; SD, standard deviation. 

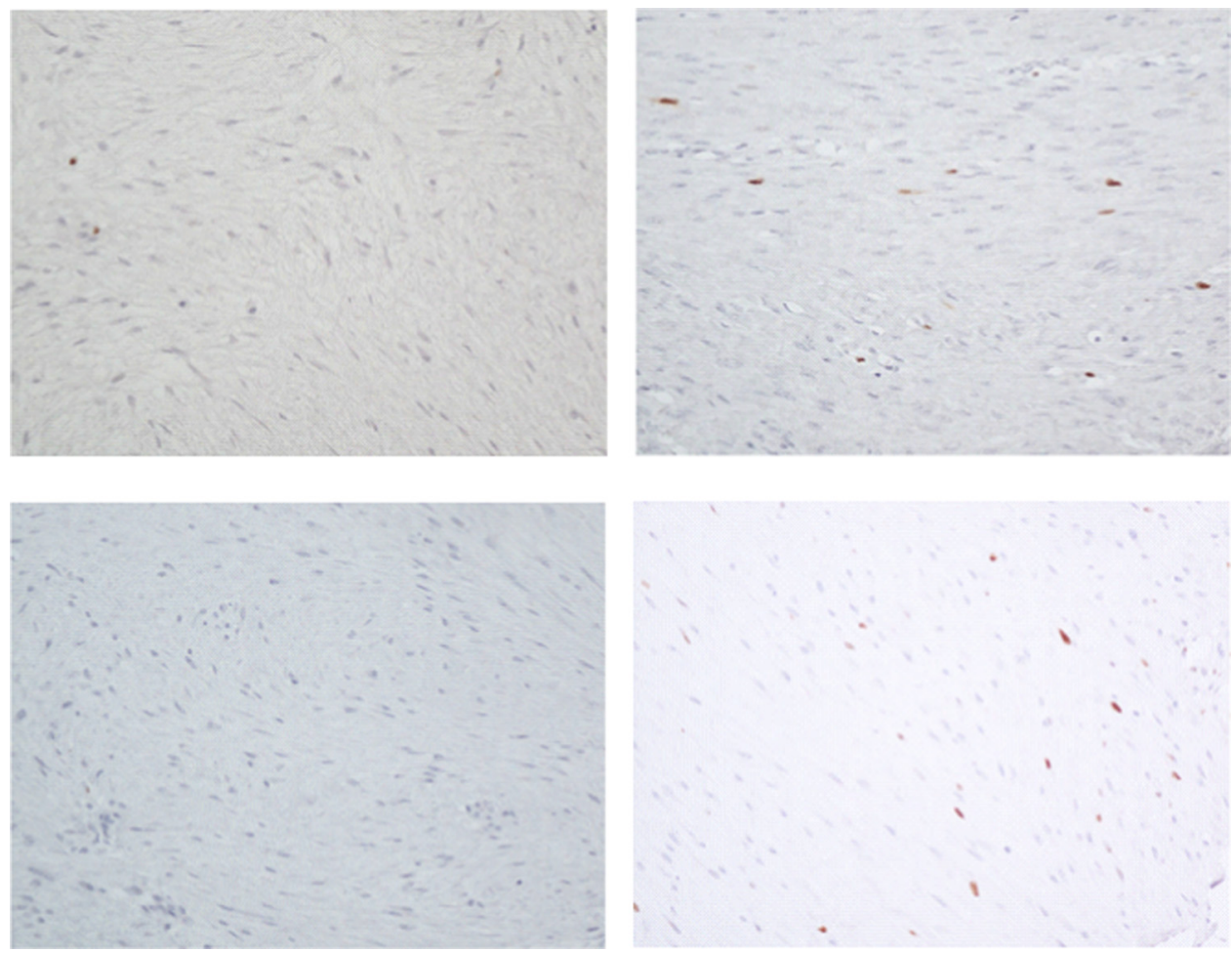

FIGURE 1 Immunostainings of cyclin A and Ki67 expression in desmoid tumor tissue: (A) low cyclin $A \leq 2.98 \%$, (B) high cyclin A $>2.98 \%$, (C) low Ki67 5 5.99\%, (D) high Ki67 < 5.99\% [Color figure can be viewed at wileyonlinelibrary.com]

no correlation between Ki67 expression and sex, tumor localization, resection margin, or postoperative radiotherapy.

\section{3 | Prognosis}

Cox univariate analysis showed that positive surgical margin (HR 5.2, 95\% Cl=1.6-16.2, $P=.005$ ), extremity location (HR 5.0, 95\% $\mathrm{Cl}=2.0-12.5, P=.001)$, high cyclin A expression $(\mathrm{HR}=1.3,95 \%$ $\mathrm{Cl}=1.0-1.5, P=.02)$, and $\operatorname{sex}(\mathrm{HR} 2.6,95 \% \mathrm{Cl}=1.1-6.2, P=.03)$ were associated with RFS (Table 2). Ki67 had no significant prognostic impact. In multivariate analysis, extremity location (HR 5.3, 95\% $\mathrm{Cl}=1.7-16.8, P=.005$ ), positive surgical margin (HR 6.0, 95\% $\mathrm{Cl}=1.6-22.5, P=.008)$, and high cyclin A expression (HR 1.9, 95\% $\mathrm{Cl}=1.1-3.2, \quad P=.02) \quad$ were independent prognostic variables (Table 2). Multivariate analyzes including only two factors retained the significance for cyclin $A$ in models including either surgical margin $(P=.005)$ or location $(P=.01)$.

All 9 alternative cut-offs indicated a higher risk of progression with high cyclin A values; however, the cut-offs at the 70-90 percentiles

TABLE 2 Cox univariate and multivariate analysis of recurrence-free survival

\begin{tabular}{|c|c|c|c|c|}
\hline & \multicolumn{2}{|l|}{ Univariate } & \multicolumn{2}{|l|}{ Multivariate } \\
\hline & HR $(95 \% \mathrm{Cl})$ & $P$-value & HR $(95 \% \mathrm{Cl})$ & $P$-value \\
\hline Positive surgical margin ${ }^{a}$ & $5.2(1.6-16.2)$ & .005 & $6.0(1.6-22.5)$ & .008 \\
\hline Cyclin A & $1.3(1.0-1.5)$ & .02 & $1.9(1.1-3.2)$ & .02 \\
\hline Ki67 & $1.1(0.95-1.2)$ & .2 & & \\
\hline Age & $1.0(1.0-1.0)$ & 6 & & \\
\hline Tumor size & $1.0(0.9-1.1)$ & .9 & & \\
\hline Postoperative radiotherapy ${ }^{d}$ & $1.2(0.3-5.0)$ & .8 & & \\
\hline
\end{tabular}

${ }^{\mathrm{a}} \mathrm{O}=$ positive, 1 = negative.

${ }^{\mathrm{b}} 0=$ other, $1=$ extremities.

${ }^{\mathrm{c}} 0=$ female, $1=$ male.

${ }^{\mathrm{d}} \mathrm{O}=$ no, $1=$ yes. 
TABLE 3 Cox univariate analysis of cyclin A expression divided from 10th to 90th percentiles and recurrence-free survival

\begin{tabular}{|clcl|}
\hline Cut-off \% & Cut-off value & HR $(95 \% \mathrm{CI})$ & $P$-value \\
\hline 10 & 0.72 & $24.3(0.1-9958.1)$ & .3 \\
\hline 20 & 0.91 & $1.4(0.4-4.9)$ & .6 \\
\hline 30 & 1.08 & $2.0(0.7-5.9)$ & .2 \\
\hline 40 & 1.37 & $1.4(0.6-3.5)$ & .5 \\
\hline 50 & 1.54 & $1.6(0.7-3.9)$ & .3 \\
\hline 60 & 1.76 & $1.6(0.7-4.0)$ & .3 \\
\hline 70 & 2.42 & $2.8(0.2-6.8)$ & .02 \\
\hline 80 & 2.98 & $3.5(1.4-8.6)$ & .006 \\
\hline 90 & 3.55 & $2.8(0.9-8.4)$ & .07 \\
\hline
\end{tabular}

yielded the most consistent and significant association with prognosis (Table 3 ). The lowest cut-off at $0.72 \%$ displayed a very high hazard rate for progression, but the confidence levels were extremely wide due to only one recurrence in the low proliferation group. RFS according to cyclin A levels at the $80 \%$ percentile cut-off at $2.98 \%$ showed a hazard rate of $3.5(P=.006)$ and is shown in Figure 2. None of the nine alternative cut-off values for Ki67 yielded any significant association with RFS. HR varied between 0.9 and 2.3 , with the highest HR (2.3) at the 70th percentile (5.99\%), with a P-value of .07 (Supporting Information Table 1).

\section{4 | DISCUSSION}

In the present study, high cyclin A was significantly associated with postoperative RFS in desmoid tumors, whereas Ki67 showed

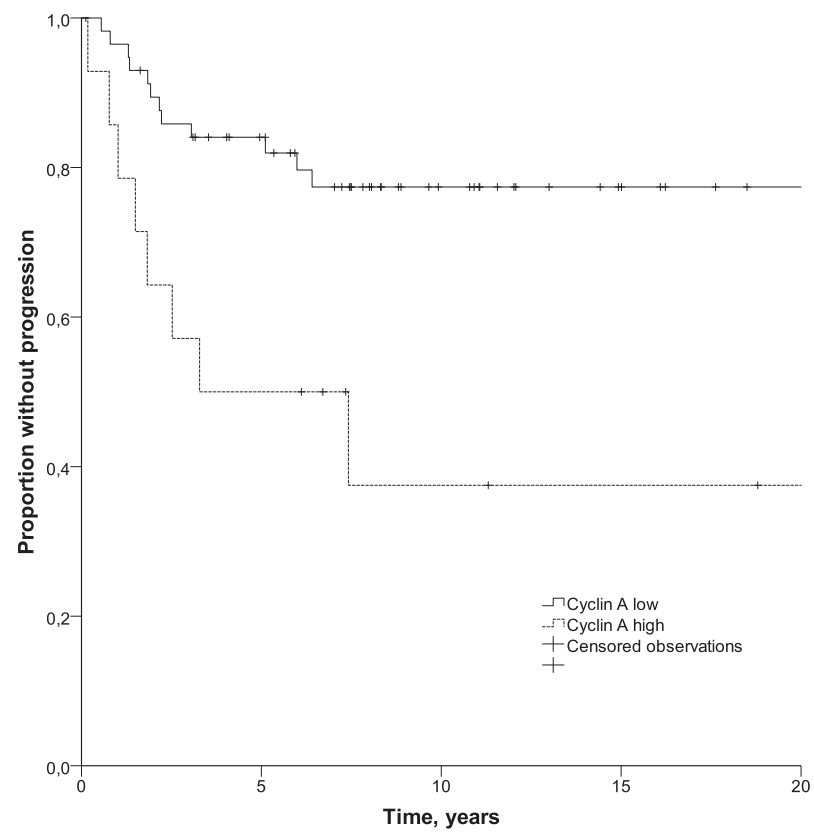

FIGURE 2 Recurrence-free survival in 72 patients with operated desmoid tumors according to cyclin A expression with a $2.98 \%$ cut-point only a nonsignificant trend toward being prognostic. Proliferation biomarkers have not previously been extensively studied in desmoid tumors. To our knowledge, cyclin A expression has not been investigated before in desmoid tumors, whereas only a few studies have investigated the prognostic impact of $\mathrm{Ki67}$, with conflicting results. $\mathrm{Ki} 67$ is an established prognostic and predictive tool in various cancer types, such as breast cancer, soft-tissue sarcomas, and neuroendocrine neoplasms, and it is probably the most extensively studied proliferation marker. ${ }^{13-15}$

Expression of Ki67 and cyclin A was low compared with malignant mesenchymal tumors. The median $\mathrm{Ki} 67$ index was $3.9 \%$ (mean $4.6 \%$ ) and the median percentage of cyclin A positive nuclei was $1.5 \%$ (mean $1.9 \%$ ). In a previous study of sarcomas by our group, the corresponding values were $18 \%$ and $11 \%$, respectively. ${ }^{11,16}$ In another series of 193 patients with soft-tissue sarcomas of the trunk and extremities, the median Ki67 index was $30 \%{ }^{17}$ Furthermore, in 216 patients with nonvisceral soft-tissue sarcoma, the median Ki67 index was $12 \% .{ }^{18}$ In desmoid tumors, previously published data on Ki67 expression agree with the present study in that proliferation is low, with mean Ki67 rates ranging from unmeasurable to $8.7 \% .{ }^{19-24}$ Visual analysis in four studies with $38,15,31$, and 51 patients yielded mean Ki67 proportions of $3.0 \%, 3.2 \%, 8.7 \%$, and $1.9 \%$, respectively. ${ }^{21-23,25}$ Digital Ki67 scoring in a study of 42 patients with desmoid tumors yielded a mean rate of $6 \%,{ }^{24}$ whereas another study of 80 patients reported a mean value of $8.1 \%$, with the highest scores in extraabdominal tumors. ${ }^{20}$ In some publications without explicit numerical values, Ki67 was stated to be positive from $3 \%$ to $38 \%$ of tumors, with various cut-off values from $2 \%$ to $5 \%,{ }^{26-28}$ whereas others only briefly mentioned that proliferation was low. ${ }^{29,30}$

Three previous studies have evaluated $\mathrm{Ki} 67$ as a prognostic biomarker in desmoid tumors. ${ }^{23,31,32}$ One of these, however, studied a mixture of sarcomas and desmoid tumors and separate results from desmoid tumors were not reported. ${ }^{31}$ One of the remaining studies with 33 patients with desmoid tumors reported an association with high $\mathrm{Ki} 67$ and short disease-free survival, whereas Ki67 was not prognostic in the other study $(n=51) .{ }^{23,32}$ Despite the fact that $\mathrm{Ki} 67$ and cyclin A were significantly correlated in the present study, high Ki67 labeling was only weakly and non-significantly prognostic in contrast to cyclin A.

Overexpression of cyclin $A$ has been reported to be an unfavorable prognostic indicator in soft-tissue sarcomas and in breast cancer, but has not, to our knowledge, been reported in desmoid tumors. ${ }^{10,11,33}$ Cyclin A regulates the cell cycle progression in S and G2 phases, whereas Ki67 is present in all the cell cycle phases besides the resting phase GO. Hypothetically, the more restricted expression of cyclin $A$ in cells committed to cell division may explain the superior accuracy of cyclin A in comparison with Ki67. In agreement with our findings in desmoid tumors, previous studies suggest a superior prognostic value for cyclin A also in softtissue sarcomas and colorectal cancer. ${ }^{11,33}$ 
The TMA technique enables an efficient immunohistochemical evaluation of large tumor materials, albeit TMA cores may yield different scores than whole sections due to intratumoral variations, which may be a limitation of the present study. However, TMA has been validated for fibroblastic neoplasms, including desmoid tumors, with a Ki67 concordance of $96 \%$ between whole sections and triplicate TMA cores. ${ }^{31}$ The relatively homogenic tissue of desmoid tumors probably makes it especially suitable for TMA. The major strengths of this study include histologically re-evaluated and confirmed diagnosis of all cases, objective proliferation scoring by quantitative image analysis, and a long follow-up duration.

\section{5 | CONCLUSIONS}

Cyclin A overexpression is an independent prognostic factor of relapse in desmoid tumors after resection.

\section{ACKNOWLEDGMENTS}

We thank Päivi Peltokangas and Eveliina Markkula for technical assistance. The study was supported by the Helsinki University Hospital Research funds. Finska Läkaresällskapet and Finnish Society for Oncology supported KS and Sigrid Jusélius Foundation and Medicinska Understödsföreningen Liv och Hälsa supported $\mathrm{CH}$.

\section{CONFLICTS OF INTEREST}

All authors declare no conflicts of interest.

\section{ORCID}

Kirsi Santti (D) http://orcid.org/0000-0002-5557-6985

\section{REFERENCES}

1. Law ME, Corsino PE, Narayan S, Law BK. Cyclin-dependent kinase inhibitors as anticancer therapeutics. Mol Pharmacol. 2015; 88:846-852.

2. Turner NC, Ro J, André F, et al. Palbociclib in hormone-receptorpositive advanced breast cancer. N Engl J Med. 2015;373: 209-219.

3. Santti K, Beule A, Tuomikoski L, et al. Radiotherapy in desmoid tumors: treatment response, local control, and analysis of local failures. Strahlenther Onkol. 2017;193:269-275.

4. Crago AM, Chmielecki J, Rosenberg $M$, et al. Near universal detection of alterations in CTNNB1 and Wnt pathway regulators in desmoid-type fibromatosis by whole-exome sequencing and genomic analysis. Genes Chromosomes Cancer. 2015;54: 606-615.

5. Sinha A, Tekkis PP, Gibbons DC, Phillips RK, Clark SK. Risk factors predicting desmoid occurrence in patients with familial adenomatous polyposis: a meta-analysis. Colorectal Dis. 2011;13: 1222-1229.

6. Gurbuz AK, Giardiello FM, Petersen GM, et al. Desmoid tumours in familial adenomatous polyposis. Gut. 1994;35:377-381.
7. Yao X, Corbett T, Gupta A, et al. A systematic review of active treatment options in patients with desmoid tumours. Curr Oncol. 2014;21:e613-e629.

8. Janssen ML, van Broekhoven DLM, Cates JMM, et al. Meta-analysis of the influence of surgical margin and adjuvant radiotherapy on local recurrence after resection of sporadic desmoid-type fibromatosis. Br J Surg. 2017;104:347-357.

9. Crago AM, Denton B, Salas S, et al. A prognostic nomogram for prediction of recurrence in desmoid fibromatosis. Ann Surg. 2013;258:347-353.

10. Ahlin C, Zhou W, Holmqvist $M$, et al. Cyclin A is a proliferative marker with good prognostic value in node-negative breast cancer. Cancer Epidemiol Biomarkers Prev. 2009;18:2501-2506.

11. Huuhtanen RL, Blomqvist CP, Böhling TO, et al. Expression of cyclin A in soft tissue sarcomas correlates with tumor aggressiveness. Cancer Res. 1999;59:2885-2890.

12. Tretiakova MS, Wei W, Boyer HD, et al. Prognostic value of Ki67 in localized prostate carcinoma: a multi-institutional study of $>1000$ prostatectomies. Prostate Cancer Prostatic Dis. 2016;19: 264-270.

13. Garcia-Carbonero R, Sorbye H, Baudin E, et al. ENETS consensus guidelines for high-grade gastroenteropancreatic neuroendocrine tumors and neuroendocrine carcinomas. Neuroendocrinology. 2016; 103:186-194.

14. Dowsett M, Nielsen TO, A'Hern R, et al. Assessment of Ki67 in breast cancer: recommendations from the International Ki67 in breast cancer working group. J Natl Cancer Inst. 2011;103:1656-1664.

15. Hoos A, Stojadinovic A, Mastorides S, et al. High Ki-67 proliferative index predicts disease specific survival in patients with high-risk soft tissue sarcomas. Cancer. 2001;92:869-874.

16. Huuhtanen RL, Blomqvist CP, Wiklund TA, et al. Comparison of the $\mathrm{Ki}-67$ score and S-phase fraction as prognostic variables in soft-tissue sarcoma. Br J Cancer. 1999;79:945-951.

17. Hasegawa T, Yamamoto S, Yokoyama R, Umeda T, Matsuno $\mathrm{Y}$, Hirohashi S. Prognostic significance of grading and staging systems using MIB-1 score in adult patients with soft tissue sarcoma of the extremities and trunk. Cancer. 2002;95:843-851.

18. Jensen V, Brandt sorensen S, Bentzen SM, et al. Proliferative activity (MIB-1 index) is an independent prognostic parameter in patients with high-grade soft tissue sarcomas of subtypes other than malignant fibrous histiocytomas: a retrospective immunohistological study including 216 soft tissue sarcomas. Histopathology. 1998;32:536-546.

19. Jilong $\mathrm{Y}$, Jian $\mathrm{W}$, Xiaoyan Z, Xiaoqiu L, Xiongzeng Z. Analysis of APC/ beta-catenin genes mutations and Wnt signalling pathway in desmoid-type fibromatosis. Pathology. 2007;39:319-325.

20. Stalinska L, Turant M, Tosik D, et al. Analysis of pRb, p16INK4A proteins and proliferating antigens: PCNA, Ki-67 and MCM5 expression in aggressive fibromatosis (desmoid tumor). Histol Histopathol. 2009;24:299-308.

21. Lin XY, Wang L, Zhang Y, Dai SD, Wang EH. Variable Ki67 proliferative index in 65 cases of nodular fasciitis, compared with fibrosarcoma and fibromatosis. Diagn Pathol. 2013;8:50.

22. Saito T, Oda Y, Tanaka K, et al. Beta-catenin nuclear expression correlates with cyclin D1 overexpression in sporadic desmoid tumours. J Pathol. 2001;195:222-228.

23. Machado V, Troncoso S, Mejías L, Idoate MÁ, San-Julián M. Risk factors for local recurrence of fibromatosis. Rev Esp Cir Ortop Traumatol. 2017;61:82-87.

24. Ferenc T, Sygut J, Tosik D, et al. Analysis of p27KIP1 protein and Ki-67 expression in aggressive fibromatosis (desmoid tumor). Pol $\mathrm{J}$ Pathol. 2006;57:187-191.

25. Dubova EA, Sidorenko TV, Shchyogolev Al, Adamyan AA. Immunohistochemical characteristics of desmoid tumors. Bull Exp Biol Med. 2012;152:743-747. 
26. Leithner A, Gapp M, Radl R, et al. Immunohistochemical analysis of desmoid tumours. J Clin Pathol. 2005;58:1152-1156.

27. Gebert C, Hardes J, Kersting C, et al. Expression of beta-catenin and p53 are prognostic factors in deep aggressive fibromatosis. Histopathology. 2007;50:491-497.

28. Mueller C, Croner R, Klein P, Grützmann R, Vassos N. Primary and recurrent sporadic desmoids: Prognostic factors influencing recurrence-free survival after complete gross resection. Int J Surg. 2016;31:63-70.

29. Wang Y, Guo W, Sun K, et al. Postoperative recurrence of desmoid tumors: clinical and pathological perspectives. World I Surg Oncol. 2015;13:26-26.

30. Kouho H, Aoki T, Hisaoka M, Hashimoto H. Clinicopathological and interphase cytogenetic analysis of desmoid tumours. Histopathology. 1997;31:336-341.

31. Hoos A, Urist MJ, Stojadinovic A, et al. Validation of tissue microarrays for immunohistochemical profiling of cancer specimens using the example of human fibroblastic tumors. Am J Pathol. 2001;158:1245-1251.

32. Brueckl WM, Preuss JM, Wein A, et al. Ki-67 expression and residual tumour $(\mathrm{R})$ classification are associated with disease-free survival in desmoid tumour patients. Anticancer Res. 2001;21: 3615-3620.

33. Handa K, Yamakawa M, Takeda H, Kimura S, Takahashi T. Expression of cell cycle markers in colorectal carcinoma: superiority of cyclin A as an indicator of poor prognosis. Int J Cancer. 1999;84:225-233.

\section{SUPPORTING INFORMATION}

Additional supporting information may be found online in the Supporting Information section at the end of the article.

How to cite this article: Santti K, Ihalainen H, Rönty $M$, et al. High cyclin A expression, but not Ki67, is associated with early recurrence in desmoid tumors. J Surg Oncol.

2018;118:192-198. https://doi.org/10.1002/jso.25121 